\title{
CONCEPÇÃO DE CIÊNCIA PARA JOVENS DE DUAS INSTITUIÇÕES DE ENSINO DO RIO DE JANEIRO
}

\section{CONCEPTION OF SCIENCE FOR YOUTH FROM TWO EDUCATIONAL INSTITUTIONS IN RIO DE JANEIRO}

\author{
Claudia Maria de Oliveira Sordillo ${ }^{1 *}$, Margareth Braz Ramos², Edna Maria Querido de Oliveira \\ Chamon ${ }^{3}$ \\ 1 Doutoranda do Programa de Pós-Graduação em Educação da Universidade Estácio de Sá, Rio de Janeiro, RJ, Brasil, \\ csordillo@yahoo.com.br \\ 2 Doutoranda do Programa de Pós-Graduação em Educação da Universidade Estácio de Sá, Rio de Janeiro, RJ, Brasil, \\ mbrazramos1@gmail.com \\ 3 Docente do Programa de Pós-Graduação em Educação da Universidade Estácio de Sá, Rio de Janeiro, RJ, Brasil, \\ chamon.unesa@gmail.com \\ ${ }^{*}$ Autor de correspondência
}

\section{Resumo}

No cenário pandêmico atual as questões sobre a Ciência e sua importância na sociedade tornaram-se mais visíveis e urgentes. Por outro lado, o isolamento social causado pela COVID-19, tem intensificado as relações virtuais através das redes sociais digitais, por onde tem circulado grande número de informações, cuja veracidade nem sempre é verificada, podendo gerar insegurança e desinformação. Com o objetivo de realizar um estudo preliminar sobre as representações sociais de Ciência, e sobre as fontes de informação para o tema, entre jovens concluintes do ensino médio e outros em formação profissional, foram disponibilizados questionários em ambientes virtuais de aprendizagem de duas instituições de educação localizadas no Rio de Janeiro, uma delas de Ensino Médio Regular e outra de formação profissional. As respostas foram organizadas em planilhas, com o auxílio do editor de planilhas Excel, e apresentadas em gráficos sobre os quais se fez uma análise à luz do referencial teórico utilizado. Os resultados apontam que os estudantes das duas Instituições utilizam, com maior frequência, canais digitais do YouTube para obter informações sobre Ciência e que a maioria dos sujeitos a relaciona à produção de conhecimento e reconhece sua importância para a compreensão do mundo que os cerca.

Palavras-chave: Educação. Ciência. Ensino Médio. Formação Profissional.

\begin{abstract}
In the current pandemic scenario, questions about Science and its importance in society have become more visible and urgent. On the other hand, the social isolation caused by COVID-19 has intensified virtual relationships through digital social networks, through which a large amount of information has circulated, whose veracity is not always verified, which may generate insecurity and misinformation. In order to carry out a preliminary study on the social representations of Science, and on the sources of information for the topic, among high school graduates and others in vocational training, questionnaires were made available in virtual learning environments of two educational institutions. located in Rio de Janeiro, one of them for Regular High School and the other for professional training. The answers were organized in spreadsheets, with the help of the Excel spreadsheet editor, and presented in graphs on which an analysis was made in the light of the theoretical framework used. The results show that students from both institutions use more often digital YouTube channels to obtain information about Science and that most subjects relate it to knowledge production and recognize its importance for understanding of the world around them.
\end{abstract}

Keywords: Education. Science. High School. Professional qualification. 


\section{INTRODUÇÃO}

Desde a segunda metade do século XX as diversas descobertas científicas, principalmente no campo da genética molecular, e o rápido avanço da tecnologia da informação, têm contribuído para colocar a Ciência numa posição de destaque em vários veículos de comunicação. No entanto, em geral, a divulgação científica não mostra todo o processo de produção desse tipo de conhecimento, tendendo a ressaltar a importância de resultados parciais de pesquisas para a sociedade, mesmo que ainda haja um longo caminho de análises a percorrer antes de se tornarem disponíveis para a população. Sendo assim, algumas vezes, isso pode dar a impressão de promessas não cumpridas. Além disso, apesar de diversos estudos científicos terem aumentado a qualidade de vida da sociedade moderna, é importante deixar claro que a Ciência busca compreender os fenômenos e esse processo é contínuo e não se finaliza com uma única resposta, já que os acontecimentos estão sempre em movimento, o que modifica, também, as variáveis que incidem sobre o fenômeno.

“Nas últimas décadas, a percepção social da Ciência e da tecnologia (C\&T) tornou-se um tema de grande relevância, tanto na academia quanto na política" (CASTELFRANCHI et al, 2013). A pandemia do novo coronavírus, apesar do cenário mórbido de perdas, isolamento e solidão que criou, teve uma consequência positiva para a Ciência: a crença da sociedade em seus resultados se intensificou (ANDRADE, 2020). No entanto, apesar do protagonismo da Ciência em meio à crise sanitária que estamos vivendo, é necessário apontar que a Ciência tem seus limites e seu próprio tempo, constituindo um empreendimento de longo prazo.

A Ciência é uma produção social que exige uma ação sistematizada e, pesar de todo rigor exigido em sua produção, é realizada por seres humanos, sujeitos às crenças e mazelas de seu tempo. Para que a Ciência forneça resultados confiáveis, necessita de pesquisadores cuja formação demanda décadas de estudos, além de laboratórios e equipamentos adequados. Por isso, é fundamental um investimento contínuo (LENT, 2020).

Como ressalta Costa (2020), a pós-modernidade é orientada pelo positivismo científico, no qual o indivíduo precisa se distanciar de seus valores e crenças para buscar a verdade pura. Em épocas de crise, ao invés de evocarmos um ser supremo, passamos a recorrer à medicina, à engenharia, à tecnologia, principalmente àquela ligada às comunicações. 0 místico, religioso, sagrado foi dando lugar ao que atende aos nossos desejos e interesses, particularmente em uma sociedade capitalista e de consumo; o sábio é substituído pelo especialista. No entanto, é preciso respeitar o tempo necessário para que a Ciência desenvolva todas as etapas da pesquisa e gere resultados confiáveis, de acordo com as evidências e os debates entre pares.

As lacunas da modernidade, como a diminuição da espiritualidade, a falta de acesso universal aos produtos da Ciência, a não democratização da medicina, a ausência de um ensino crítico e dialógico, vão sendo preenchidas por um fundamentalismo religioso e político. A cibercultura, por meio das redes sociais, vai dando, assim, espaço a grupos radicais, que utilizam um discurso contra a Ciência e a favor de interesses próprios. Elian (2021) destaca que a pandemia de Covid-19 provocou a circulação de uma quantidade de informações sobre Ciência tão rápida e excessiva, que, muitas vezes, nem conseguimos verificar sua veracidade, processo esse que passou a ser chamado de "infodemia". ${ }^{1}$ As pessoas recebem as informações por meios digitais, em suas

\footnotetext{
${ }^{1}$ Segundo a Organização Pan-Americana da Saúde (OPAS), se refere a um grande aumento no volume de informações associadas a um assunto específico, que podem se multiplicar exponencialmente em pouco tempo devido a um evento específico, como a pandemia atual. Nessa situação, surgem rumores e desinformação, além da manipulação
} 
redes sociais e repassam, sem nem mesmo ler o conteúdo completo ou verificar as fontes, talvez porque confiam nos familiares e amigos de quem as receberam, ou simplesmente são influenciados pela desinformação. $\mathrm{O}$ autor associa esse fenômeno a dois fatores basicamente: 0 distanciamento da Ciência em relação à população, uma vez que $90 \%$ do conhecimento científico nacional é produzido nas universidades públicas e pouco divulgado; e a pós-verdade, termo que resume o momento atual no qual vivemos, onde as experiências pessoais e o apelo às emoções e as crenças geram mais impactos do que os fatos apoiados em evidências, comprovados pela Ciência.

A equipe de jornalismo visual da BBC News Brasil (2021), utilizando uma metodologia inspirada em um estudo desenvolvido pela ONG First Draft, especializada no combate à desinformação, analisou os posts sobre vacinas que obtiveram maiores números em interações no período de $1^{\circ}$ de dezembro de 2020 a 31 de janeiro de 2021 e que foram publicados em português pelo Facebook $^{2}$. O resultado apontou que, em geral, estes posts utilizavam um discurso contra as vacinas de Covid-19, baseado em informações falsas ou que haviam sido retiradas do contexto. Essas conversas estavam inseridas em diversos temas, como economia, Ciência, política ou religião, sendo que $66 \%$ das interações em posts antivacina ocorreram em páginas que se declaravam politicamente de direita, conservadoras ou apoiadoras da atual presidência da república.

Em uma reportagem online da Revista Isto é, de abril de 2021, intitulada "Movimento antivacina usa pandemia do coronavírus como megafone", ressalta-se que a desinformação na internet pode ser cuidadosamente organizada para este fim. Cita-se o caso de um documentário produzido na França, sob o título "Hold-Up", visto por milhares de pessoas, que denunciava uma suposta manipulação global em torno da pandemia, da qual a própria vacina faria parte. Na mesma reportagem, Christine Czerniak, responsável por ações mitigadoras da desinformação junto à Organização Mundial da Saúde (OMS), alertava para o grande risco da circulação de informações incorretas, pois já teria havido diversos casos de óbitos de pessoas que se envenenaram depois da ingestão de metanol ou por meio da utilização inadequada de produtos de limpeza, na tentativa de combater o coronavírus, já que foram informados erroneamente pelas Redes Virtuais que este seria um tratamento eficaz.

Sabe-se que a informática permitiu a criação do ciberespaço, conectando mundialmente os computadores e ampliando a comunicação humana (CARVALHO, 2011). Por essa rede podem ser veiculadas incontáveis mensagens, sem distinção de títulos ou classes sociais entre os sujeitos, ou qualquer tipo de burocracia para postagem de informações, proporcionando a igualdade entre os autores e receptores, que expressam diferentes representações de mundo. Essa diversidade de informações e opiniões, no entanto, pode provocar incertezas, o que leva à adoção de uma gama de estratégias para que determinadas ideias prevaleçam sobre outras (CAVALHEIRO; BRANDÃO, 2019), podendo gerar uma disputa de poder, e facilitar a manipulação política e ideológica

De acordo com Guareschi, Amon e Guerra (2019), estamos na era da pós-verdade, onde a influência sobre a opinião pública se dá, predominantemente, por meio do apelo às crenças e emoções e não pela exposição objetiva dos fatos. Vive-se uma época de apego às próprias

de informações com intenção duvidosa. Na era da informação, esse fenômeno é amplificado pelas redes sociais e se alastra mais rapidamente, como um vírus. https://iris.paho.org/handle/10665.2/52054?locale-attribute=pt

${ }^{2}$ Rede social virtual criada no final de 2003, na Universidade de Harward, por Mark Zuckerberg, com o objetivo inicial de facilitar o compartilhamento de informações, entre universitários, na web. Hoje em dia é um serviço gratuito, por meio do qual seus usuários administram o próprio espaço pessoal, através da sua página de início, podendo criar comunidades de amigos e conhecidos de maneira virtual. https://conceitos.com/facebook/ 
convicções e ao ceticismo quanto ao verdadeiro diálogo. Observam-se, tanto na comunicação impressa, como na digital, espaços de antagonismo, onde se estabelecem verdadeiras disputas entre grupos que apresentam opiniões divergentes (GUARESCHI; AMON; GUERRA, 2019). Ao mesmo tempo, "[...] o ciberespaço oferece o que há de mais rico na dinâmica identitária de qualquer cultura, uma vez que a identidade e a cultura de um povo são especificidades que emergem de mútuas influências" (ALVES-MAZZOTTI; CAMPOS, 2014, p. 613).

As Representações Sociais, teoria elaborada por Moscovici na década de 1960 (MOSCOVICl, 1961, 2012) constituem um fenômeno cultural cuja gênese está “[...] associada à difusão do conhecimento científico na vida social e ao fato de constituírem o equivalente do senso comum nas sociedades contemporâneas" (ALVES-MAZZOTTI; CAMPOS, 2014, p. 621). O rápido crescimento das cidades contemporâneas heterogêneas tem proporcionado a criação de vínculos sociais superficiais, temporários e desconectados de suas vizinhanças, o que caracteriza também as comunidades digitais. No entanto, é possível encontrar, no ciberespaço, redes sociais compostas por pessoas que partilham crenças e valores, trocam informações, constroem conhecimentos e comungam os mesmos objetivos, permanecendo conectadas pela semelhança de traços, por meio dos quais se identificam como grupo, o que é essencial à construção de Representações Sociais (ALVES-MAZZOTTI; CAMPOS, 2014). Para Palmonari e Cerrato (2014, p. 433), na sociedade pós-moderna, a comunicação tem papel fundamental na manutenção da coesão social, afetando e controlando "[...] o funcionamento do metassistema cognitivo individual e, portanto, o sistema de representações e as práticas sociais cotidianas associadas a ele". A maneira como o saber é veiculado determina a organização de grupos com capacidade crítica para compreender a sociedade em que vivem e reivindicar mudanças. Dessa forma, faz-se necessária a realização de estudos que analisem a configuração do discurso na área de divulgação científica e como esse conhecimento é percebido pela opinião pública (CALDAS, 2011), de modo a contribuir para o avanço da desconstrução de informações incorretas que circulam em redes sociais e da organização de uma cultura científica, com cidadãos autônomos e participativos, essencial na sociedade contemporânea altamente tecnicizada.

Conforme Reis (1982, 2002, p. 76): "Durante muito tempo, a divulgação se limitou a contar ao público os encantos e os aspectos interessantes e revolucionários da ciência." O jornalismo científico brasileiro ainda se baseia no "modelo do déficit", que considera a completa ignorância da população em relação aos conhecimentos científicos e, por isso, as informações por ele divulgadas, teriam uma função libertadora, constituindo-se, no entanto, de um conteúdo descontextualizado, de aplicação imediata dos resultados promissores da Ciência, sem levar em conta o percurso necessário para obtê-los, nem o cenário histórico e cultural em que foram desenvolvidos (MOREIRA; MASSARANI, 2002). Por isso, Candotti (2002) salienta a responsabilidade social do cientista na divulgação de suas pesquisas para o público leigo, e a importância da incorporação da verba destinada a esse tipo de atividade nos projetos de financiamento governamentais, pois pela voz do sujeito que a produz, a imagem pública da Ciência chega mais perto da realidade. Além disso, fornece subsídios mais confiáveis para a atualização de materiais didáticos.

Consideramos que a escola, espaço de educação formal, deve ser a principal responsável por apresentar conhecimentos científicos e tecnológicos, numa perspectiva crítica, sobretudo em um país de dimensões continentais como o nosso, onde o pequeno número de espaços culturais e de divulgação científica está localizado nos grandes centros urbanos. Sendo assim, espera-se que os alunos que estão finalizando a educação básica, seja para entrar no mercado de trabalho seja para ingressar em uma universidade, ou ambos, tenham desenvolvido competências para 
compreender a natureza da Ciência e os impactos que ela pode causar em nosso cotidiano. Desse modo, podem dispor de elementos que os auxiliem na escolha de suas profissões, bem como contribuam em sua atuação como cidadãos participativos na tomada de decisões nas comunidades das quais fazem parte. Além disso, deverão ter desenvolvido a habilidade necessária para o acompanhamento das ações de autoridades competentes por formulação de políticas públicas e investimentos adequados em diferentes áreas, inclusive a científica.

Como ressaltou o historiador Yuval Noah Harari, em entrevista concedida à emissora alemã Deutsche Welle (DW), em 26 de abril de 2020, que apesar dos discursos de vários políticos populistas dos últimos anos que negam que fenômenos como as drásticas mudanças climáticas que estamos observando serem frutos de ações antrópicas e de outros diversos ataques à Ciência, as pessoas nunca acreditaram tanto no trabalho dos cientistas como atualmente. Para o historiador, não precisamos formar especialistas em Ciência, mas as escolas, por meio de políticas públicas adequadas, precisam se preocupar em fornecer aos indivíduos uma educação científica, que os tornem capazes de interpretar criticamente os discursos das figuras públicas e de entender os alertas dos cientistas sobre possíveis colapsos ambientais. Desse modo, Arantes e Peres (2021) destacam que é preciso utilizar estratégias de ensino inovadoras no sentido de promover o engajamento, a cooperação e a autonomia dos sujeitos nos processos de letramento e alfabetização científica. Conhecer e considerar as representações sociais de Ciência que os alunos trazem para os espaços de formação pode auxiliar os professores na escolha dos saberes a serem ensinados e das intervenções didáticas mais apropriadas no processo de ensino-aprendizagem, de modo a transformar o ensino de Ciências em uma prática social com uma perspectiva crítica (CHAMON; SANTANA, 2021). Como ressalta Candotti (2002, p. 23): "Se queremos educar um olhar, é preciso descobrir o que ele está vendo." Em 2014, um indicador de letramento científico elaborado pelo Instituto Paulo Montenegro, em parceria com o Instituto Brasileiro de Opinião Pública e Estatística (IBOPE) e duas organizações não governamentais foi aplicado para 2002 indivíduos entre 15 e 40 anos, em 92 municípios de nove regiões metropolitanas brasileiras (São Paulo, Rio de Janeiro, Belo Horizonte, Porto Alegre, Recife, Fortaleza, Salvador, Curitiba, Belém), além do Distrito Federal. Segundo os resultados da pesquisa, $51 \%$ dos sujeitos que haviam concluído o ensino fundamental apresentaram nível rudimentar de letramento científico. Esse percentual não se mostrou diferente entre os indivíduos que haviam completado o ensino médio (52\%), o que demonstrou que esse segmento da educação básica pode não ter contribuído para um avanço nos conhecimentos científicos dos pesquisados (SERRÃO et al, 2016).

Ao trabalharem com alunos do primeiro ciclo do ensino fundamental de duas escolas públicas de Santarém (Portugal), Reis, Rodrigues e Santos (2006) constataram a influência dos meios de comunicação de massa (desenhos animados, histórias em quadrinhos, filmes e telejornais) sobre a construção da concepção que as crianças elaboram acerca dos cientistas e do fazer científico. Os autores ressaltaram, ainda, a falta de intervenção da escola na análise crítica dessas ideias e na discussão de aspectos da natureza da Ciência. Assim, sugerem que os professores utilizem os meios de educação não formais como estratégias para contribuir no desenvolvimento das habilidades de análise crítica das informações pelos alunos.

No entanto, parece que as concepções que os próprios professores têm da Ciência também interferem em suas práticas pedagógicas. Na verdade, o conhecimento científico produzido nas instituições de pesquisa é reelaborado pelos autores dos livros didáticos e pelos professores, quando fazem a transposição didática para trabalhá-lo com seus alunos, transformando a linguagem científica numa linguagem mais acessível a seu público (MAZZOTTI, 2014). Assim, a escola de educação básica não trabalha com o conhecimento científico propriamente dito, mas 
sim com seu "duplo", sua representação social e, segundo Moscovici (1961, 2012), as representações sociais que um grupo elabora sobre um determinado objeto orientam e justificam suas ações em relação a ele. Diante dos desafios expostos, o presente trabalho tem o objetivo de conhecer as representações sociais de Ciência de jovens concluintes da educação básica, de duas instituições: uma da rede federal de educação, que oferece ensino médio regular e de uma instituição (SISTEMA S) ${ }^{3}$ que atende jovens estudantes que participam do Programa Jovem Aprendiz, ambas localizadas no Estado do Rio de Janeiro.

\section{CARACTERIZAÇÃO DOS SUJEITOS E LOCAIS PESQUISADOS}

As Instituições pesquisadas foram escolhidas devido às experiências das autoras com jovens que cursam ou cursaram o ensino médio. Uma delas é uma instituição federal de ensino, que desenvolve um projeto político pedagógico voltado para a formação integral do aluno, com uma carga horária de doze tempos semanais distribuídos entre as disciplinas da área de conhecimento das Ciências da natureza. Além disso, essa instituição possibilita a participação dos alunos em projetos de iniciação científica no contraturno, seja dentro do próprio colégio, ou em Instituições de pesquisas conveniadas. Recebe um público bastante heterogêneo, composto por alunos de diferentes realidades socioeconômicas, na faixa etária de 15 a 18 anos.

A outra Instituição participa do Programa Jovem Aprendiz, capacitando jovens entre 14 e 24 anos para ingresso no mercado de trabalho. O programa de aprendizagem atende jovens com perfis sociais de vulnerabilidade ou de risco social, alguns dos quais já concluíram a educação básica, enquanto outros ainda estão cursando o ensino médio.

Para facilitar a leitura e análise dos dados, passaremos a tratar o colégio federal como "Instituição 1" e a Instituição responsável pela formação profissional de jovens aprendizes como "Instituição 2".

\section{METODOLOGIA}

As autoras elaboraram um questionário em formulário Google, com questões fechadas sobre o perfil sociodemográfico dos estudantes e duas questões abertas: uma delas sobre a concepção de Ciência e a outra sobre as fontes nas quais eles costumavam buscar informações sobre o tema.

O questionário ficou disponível em ambientes virtuais de aprendizagem por 14 dias, para uma população de 585 alunos das três séries do ensino médio da Instituição 1 , e para 70 estudantes de duas turmas da Instituição 2, responsável pela formação profissional dos jovens aprendizes. Dessa forma, como a possibilidade de acesso ao público das duas Instituições não se deu de forma sistematizada, mas por adesão dos sujeitos, não temos a pretensão de confrontar os resultados obtidos nos locais pesquisados, mas sim apresentá-los separadamente.

Os dados foram organizados em planilhas, com o auxílio do editor de planilhas Excel, e foram agrupados de acordo com a similaridade das respostas. Para o cálculo de percentagens de frequência de respostas e a elaboração de tabelas e gráficos foi utilizado também o software Excel. No que tange às questões abertas foi feita a análise de conteúdo conforme Bardin (2016) para as análises de resultados.

\footnotetext{
${ }^{3} \mathrm{O}$ Sistema S é formado por um conjunto de nove instituições, cujos nomes iniciam com S, por prestarem serviços de treinamento aos profissionais dos setores da indústria, comércio e transporte, bem como desenvolverem atividades de lazer, cultura e cuidados à saúde. São mantidas a partir de contribuições das empresas dos respectivos setores.
} 


\section{RESULTADOS E DISCUSSÃO}

Da Instituição 1 participaram 37 jovens respondentes, enquanto na Instituição 2 foram obtidas 14 respostas para todas as questões formuladas. Por isso, foram feitas análises separadas para as duas instituições.

\subsection{Análise dos dados da Instituição 1}

Os dados sociodemográficos da Instituição 1 mostram realidades socioeconômicas dos sujeitos bastante heterogêneas, com renda familiar variando de menos de um a mais de dez salários-mínimos (Figura 1).

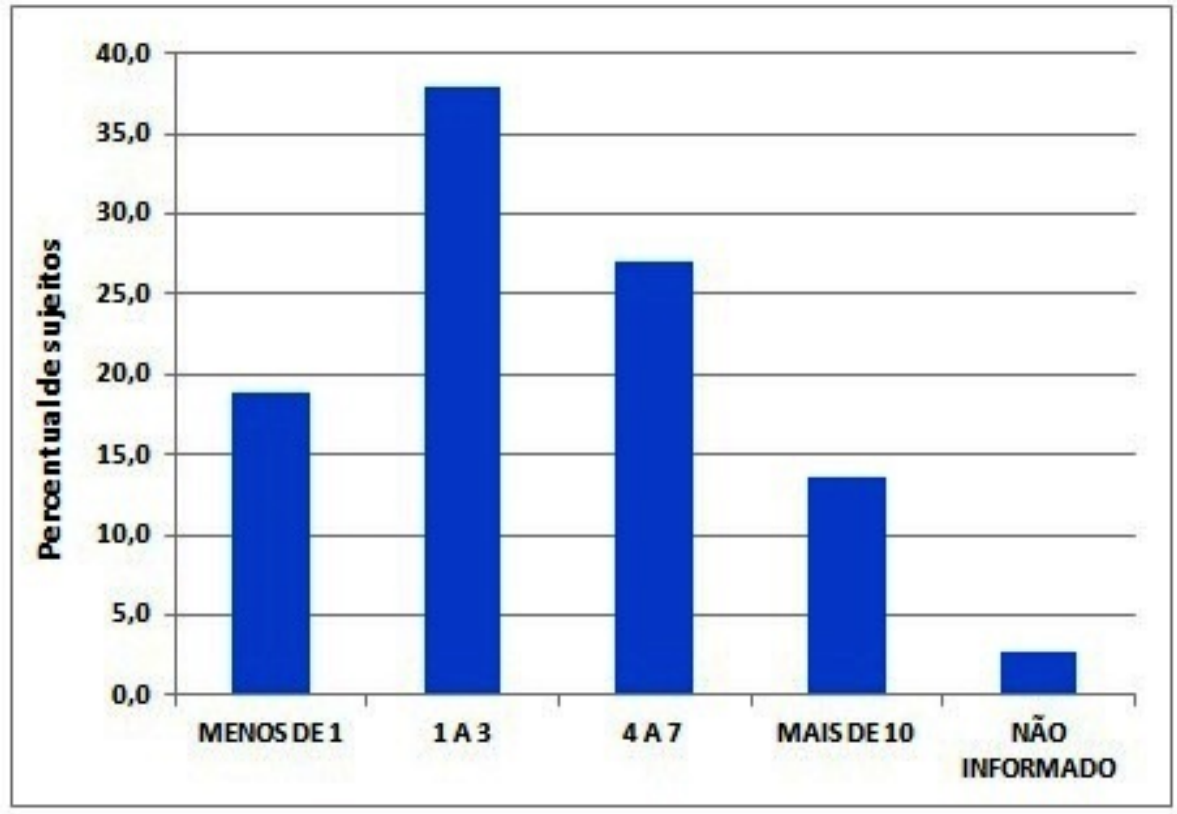

Fonte: Elaborado pelas autoras, a partir dos dados coletados.

Figura 1: Renda familiar (em número de salários-mínimos) dos sujeitos da Instituição 1

A maior parte dos participantes pertence ao gênero feminino, como se observa na Figura 2.

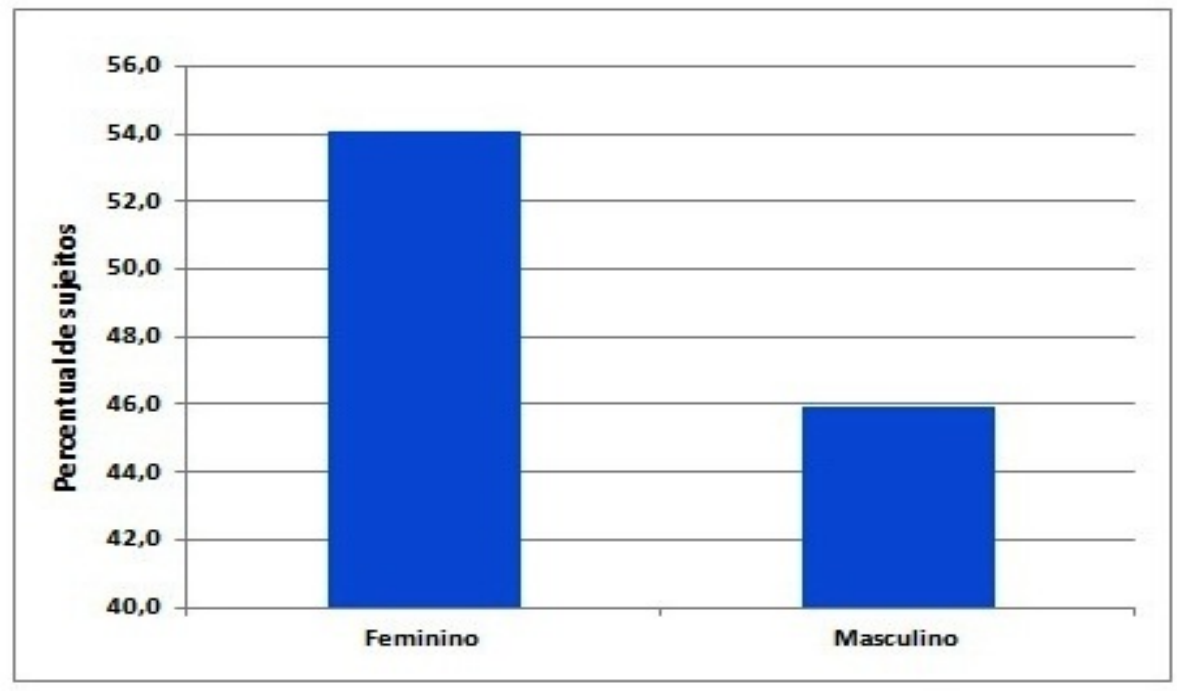

Fonte: Elaborado pelas autoras, a partir dos dados coletados.

Figura 2: Caracterização do gênero dos sujeitos da Instituição 1 
A amostra caracterizou-se por jovens na faixa etária entre 15 e 17 anos (Figura 3), sendo predominantemente brancos e pardos (Figura 4).

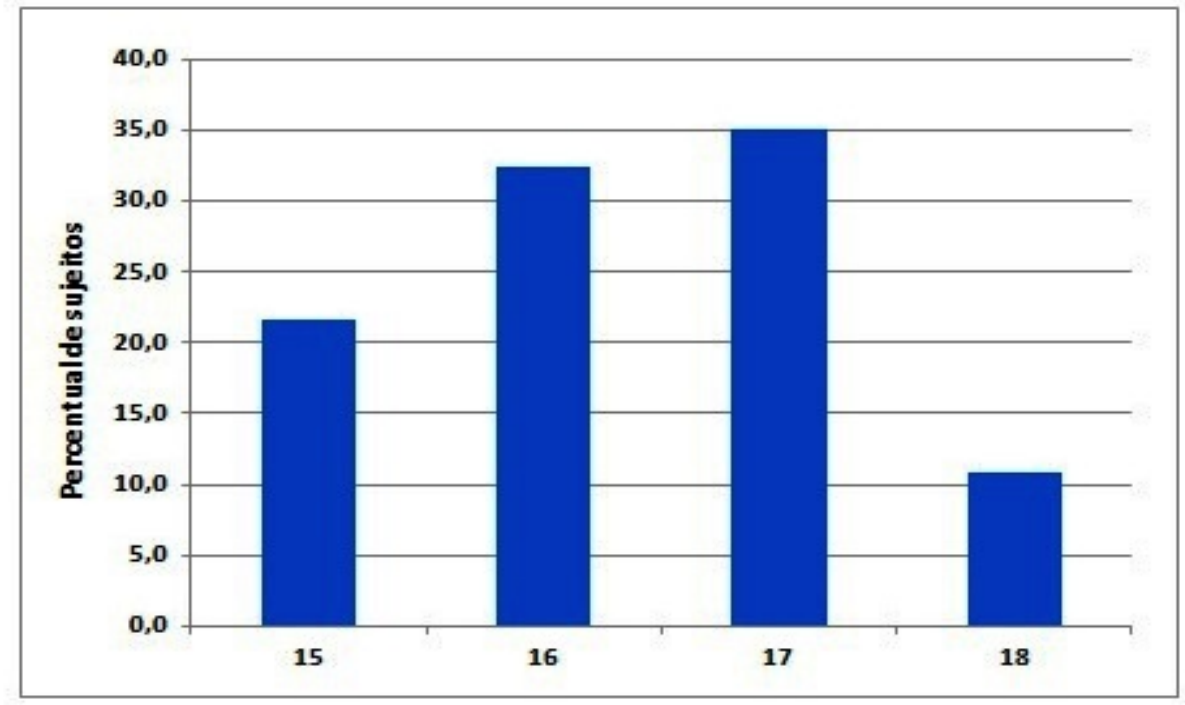

Fonte: Elaborado pelas autoras, a partir dos dados coletados.

Figura 3: Caracterização da faixa etária dos sujeitos da Instituição 1

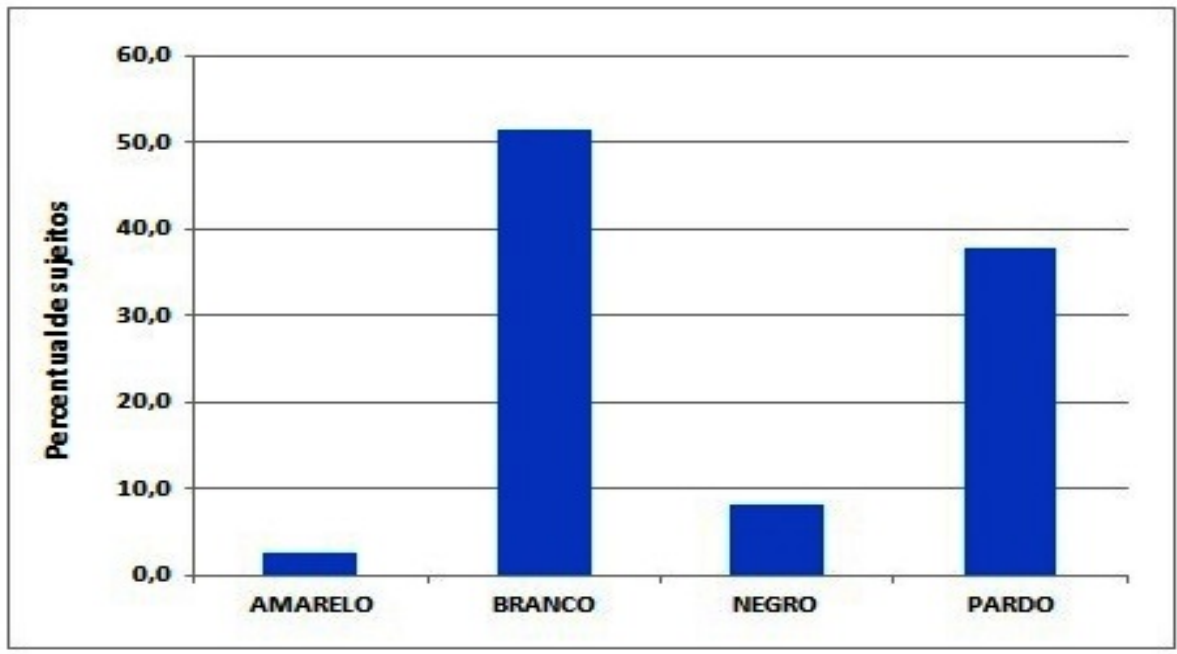

Fonte: Elaborado pelas autoras, a partir dos dados coletados.

Figura 4: Caracterização étnica dos sujeitos da Instituição 1

A Figura 5 mostra que, na Instituição 1, a questão "O que é Ciência?" resultou em respostas cujas frequências ficaram distribuídas entre (i) estudo da natureza ou do universo, (ii) conhecimento (sem especificar o tipo de conhecimento) ou descoberta, (iii) maneira de conhecer o mundo que nos cerca, (iv) estudo através de métodos padronizados e (v) estudo aprofundado de algo. A relação entre Ciência, elementos da natureza, estudo e descoberta também foi encontrada em pesquisas realizadas por Santos et al (2017) e Rodrigues et al (2019). Para alguns sujeitos, a Ciência traz benefícios à sociedade e nunca tem fim. A associação frequente com elementos da natureza e do universo e a compreensão da necessidade de métodos padronizados de estudo (remetendo ao método científico) talvez possa sofrer influência de uma exposição regular aos temas científicos, devido - possivelmente - ao número de tempos de aula de disciplinas da área 
de Ciências da natureza e ao acesso desses participantes aos projetos de iniciação científica que a Instituição 1 oferece.

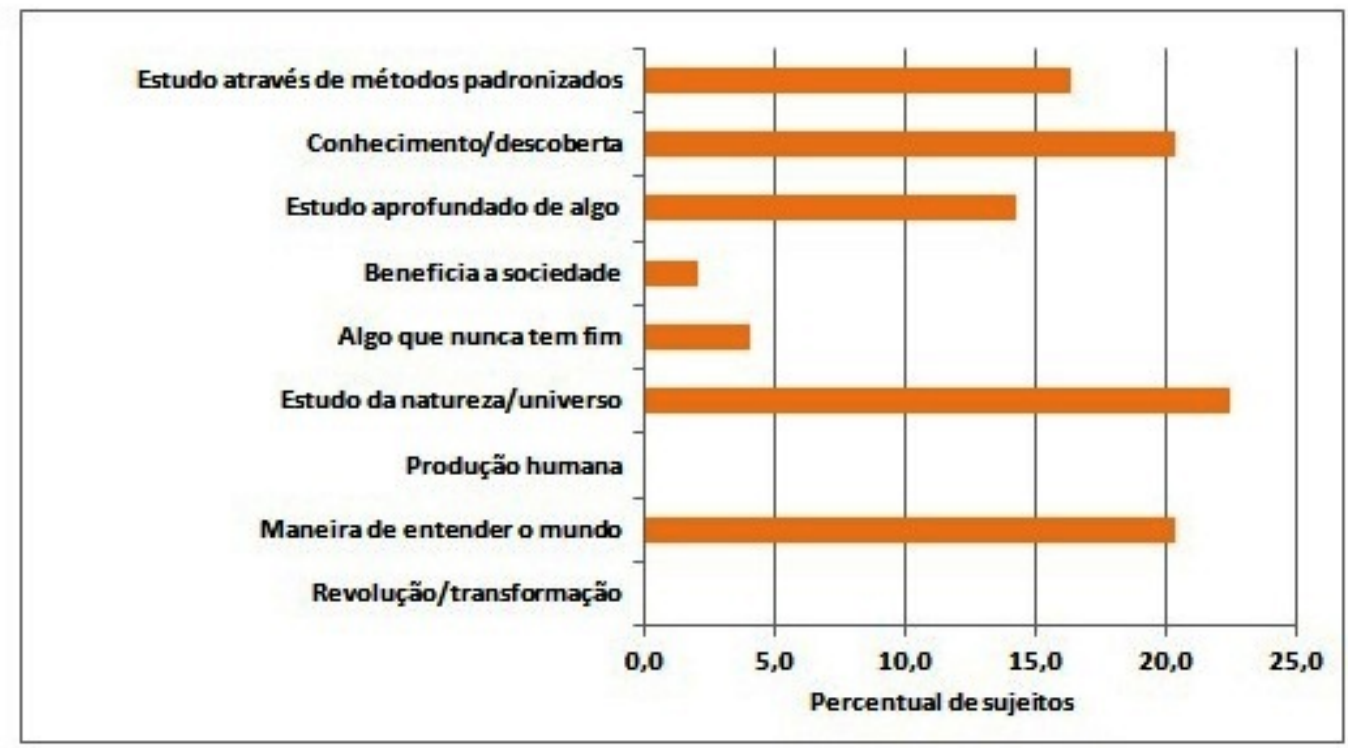

Fonte: Elaborado pelas autoras, a partir dos dados coletados.

Figura 5: Concepção de ciência dos sujeitos da Instituição 1

A Figura 6 mostra o valor que a escola tem como fonte de informação sobre Ciência para os sujeitos da Instituição 1. Com a mesma frequência aparecem os telejornais. Assim, por meio do desenvolvimento diário dos conteúdos escolares e do contato regular com as notícias que "entram" em suas casas, através de canais de TV, muitas vezes selecionados por seus familiares, estes sujeitos vão adquirindo conhecimentos sobre Ciência, sem que tenham escolhido a forma de acesso a eles. Percebe-se, ainda, a variada gama de fontes eletrônicas a que estes sujeitos têm possibilidade de acesso para obter informações sobre Ciência. Dentre elas, as que aparecem como preferenciais são o Instagram, jornais e revistas eletrônicos e canais do YouTube.

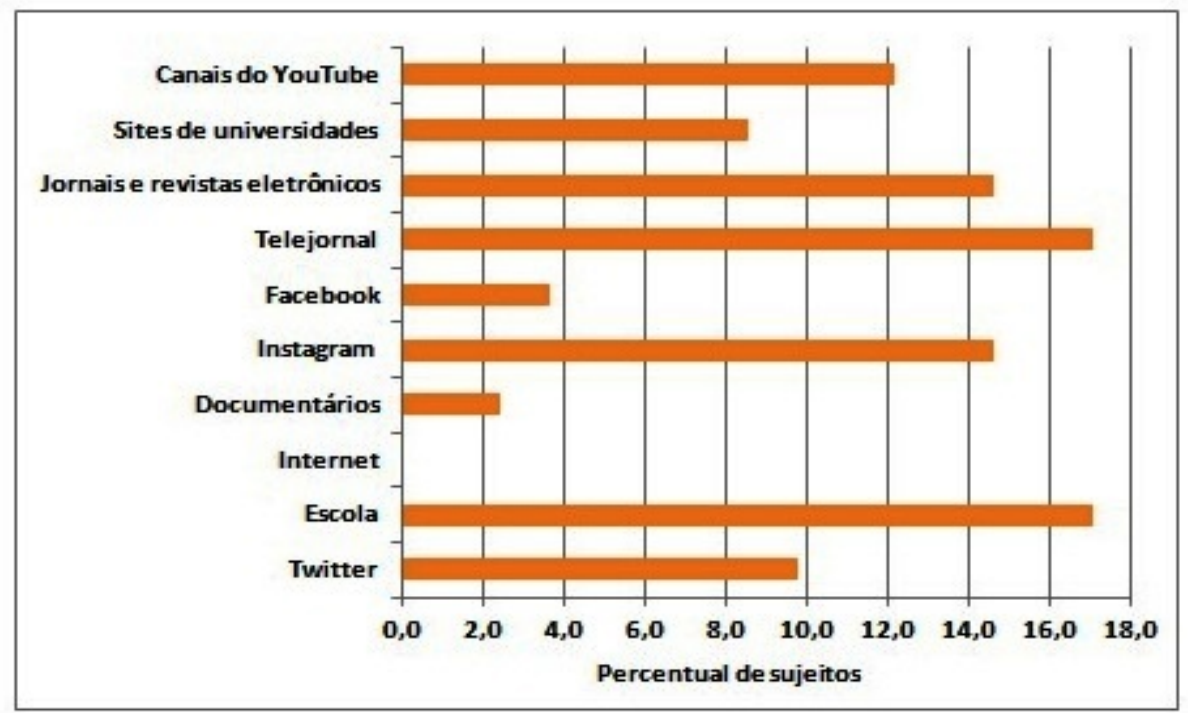

Fonte: Elaborado pelas autoras, a partir dos dados coletados.

Figura 6: Fontes de informação sobre ciência dos sujeitos da Instituição 1 
Destaca-se que o acesso a essas fontes de informação também podem influenciar a representação social de Ciência elaborada por esses sujeitos. A velocidade com a qual as informações se propagam, atualmente, tem aumentado o acesso da população em geral às rápidas transformações científicas e tecnológicas. "O senso comum não circula mais de baixo para cima, mas de cima para baixo; ele não é mais ponto de partida, mas o ponto de chegada" Moscovici (2015, 2019, p. 95). Seus conteúdos, as imagens simbólicas da Ciência em que se baseia estão sendo criados e recriados constantemente, principalmente nos grupos em que há maior popularização do conhecimento científico e tecnológico.

\subsection{Análise dos dados da Instituição 2}

A partir da análise dos dados coletados na Instituição 2, percebe-se que os sujeitos fazem parte de uma amostra socialmente vulnerável, cuja renda familiar não excede a três saláriosmínimos, como indica a Figura 7. Diante da baixa renda familiar, os jovens estão mais propensos a serem afetados pela restrição ao acesso à comunicação virtual, como a falta de internet, que se tornou mais evidente no contexto pandêmico (PEDROSO, 2020).

A amostra constituiu-se de um número igual de rapazes e moças (Figura 8), na faixa etária entre 16 e 19 anos (Figura 9), pertencentes às etnias parda, branca, negra e indígena (Figura 10).

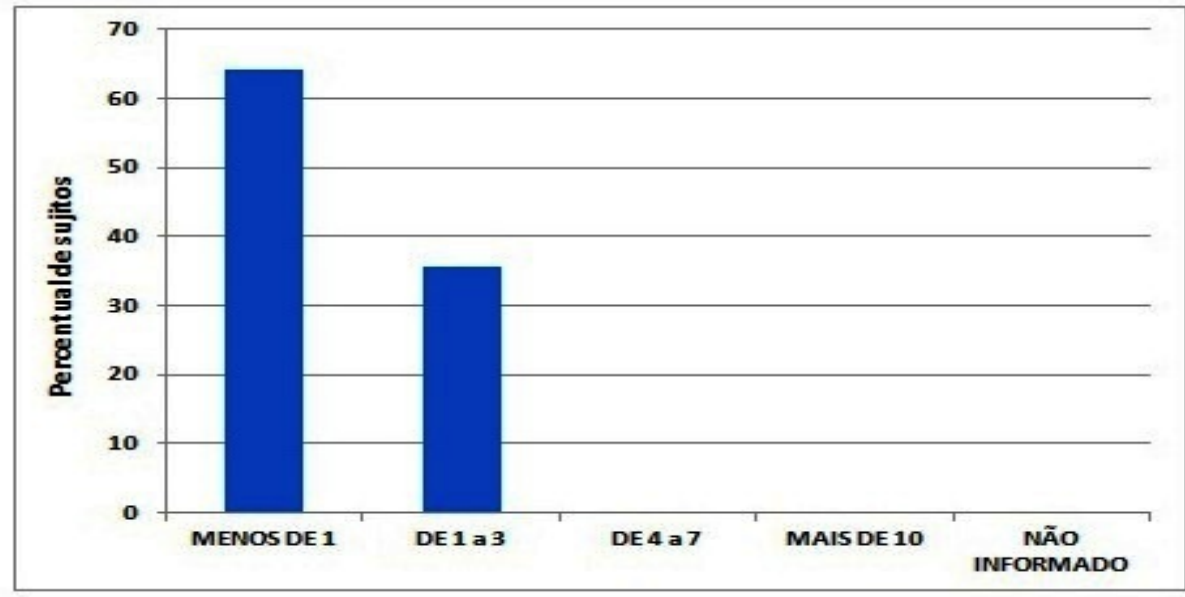

Fonte: Elaborado pelas autoras, a partir dos dados coletados.

Figura 7: Renda familiar (em número de salários-mínimos) dos sujeitos da Instituição 2

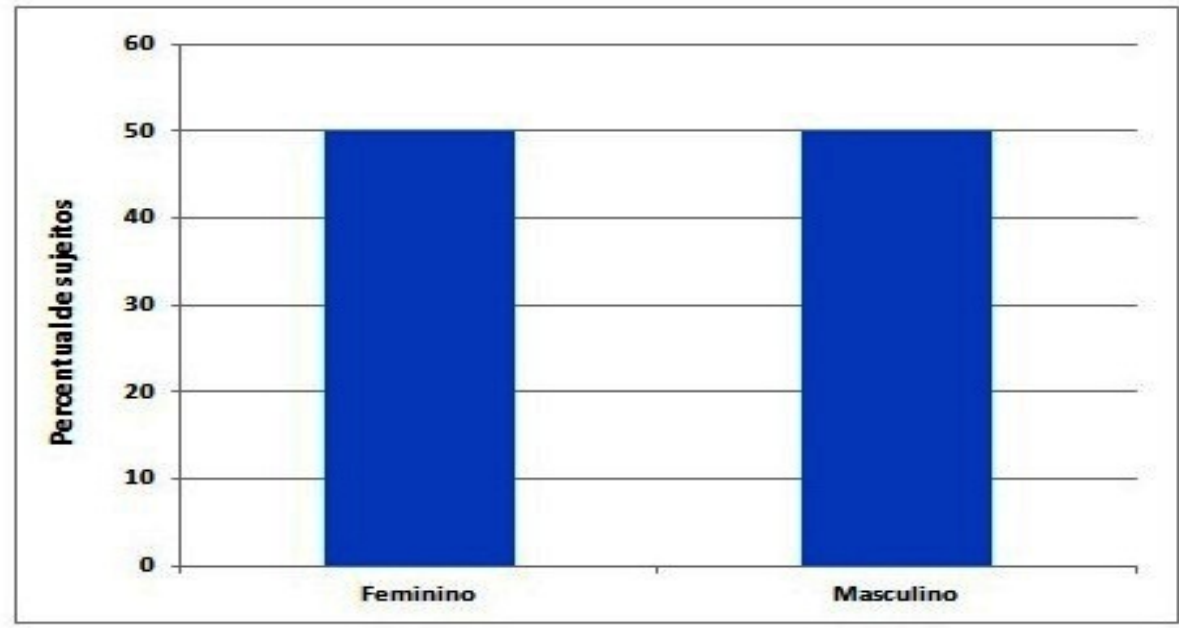

Fonte: Elaborado pelas autoras, a partir dos dados coletados. 
Figura 8: Caracterização do gênero dos sujeitos da Instituição 2

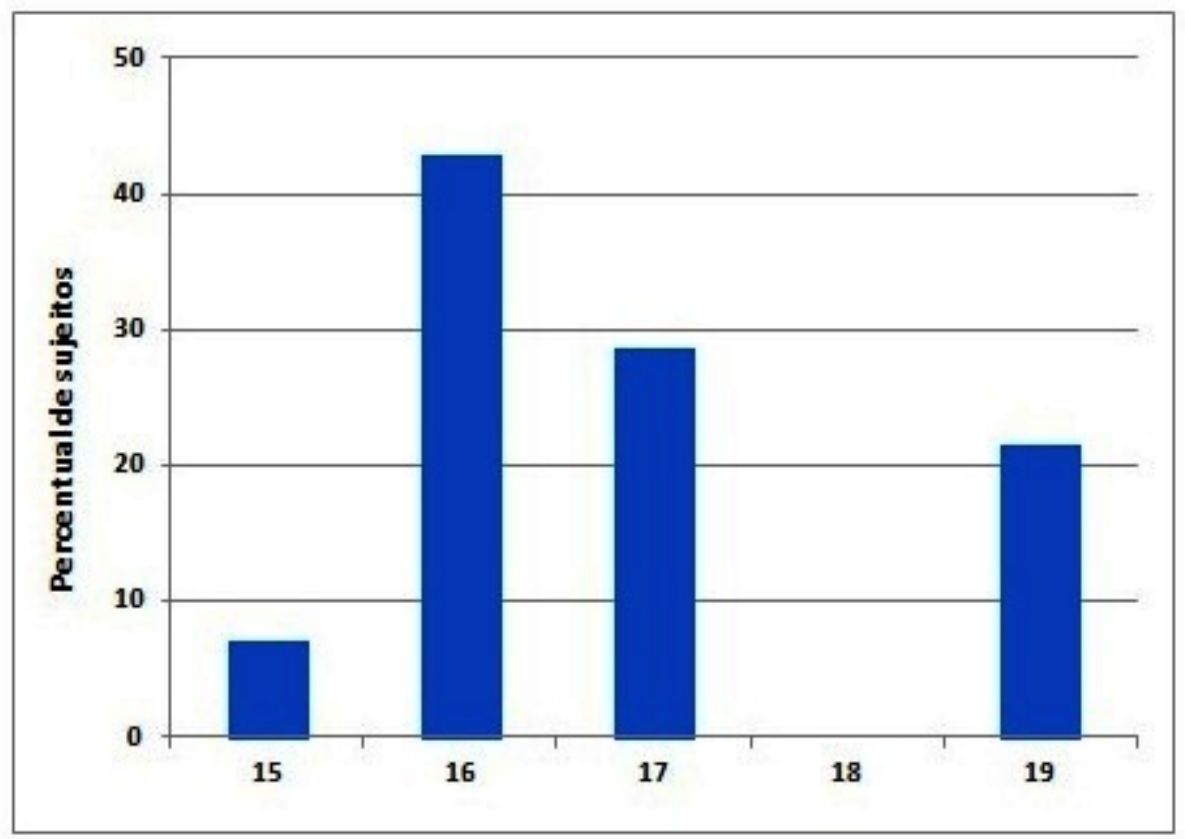

Fonte: Elaborado pelas autoras, a partir dos dados coletados.

Figura 9: Caracterização da faixa etária dos sujeitos da Instituição 2

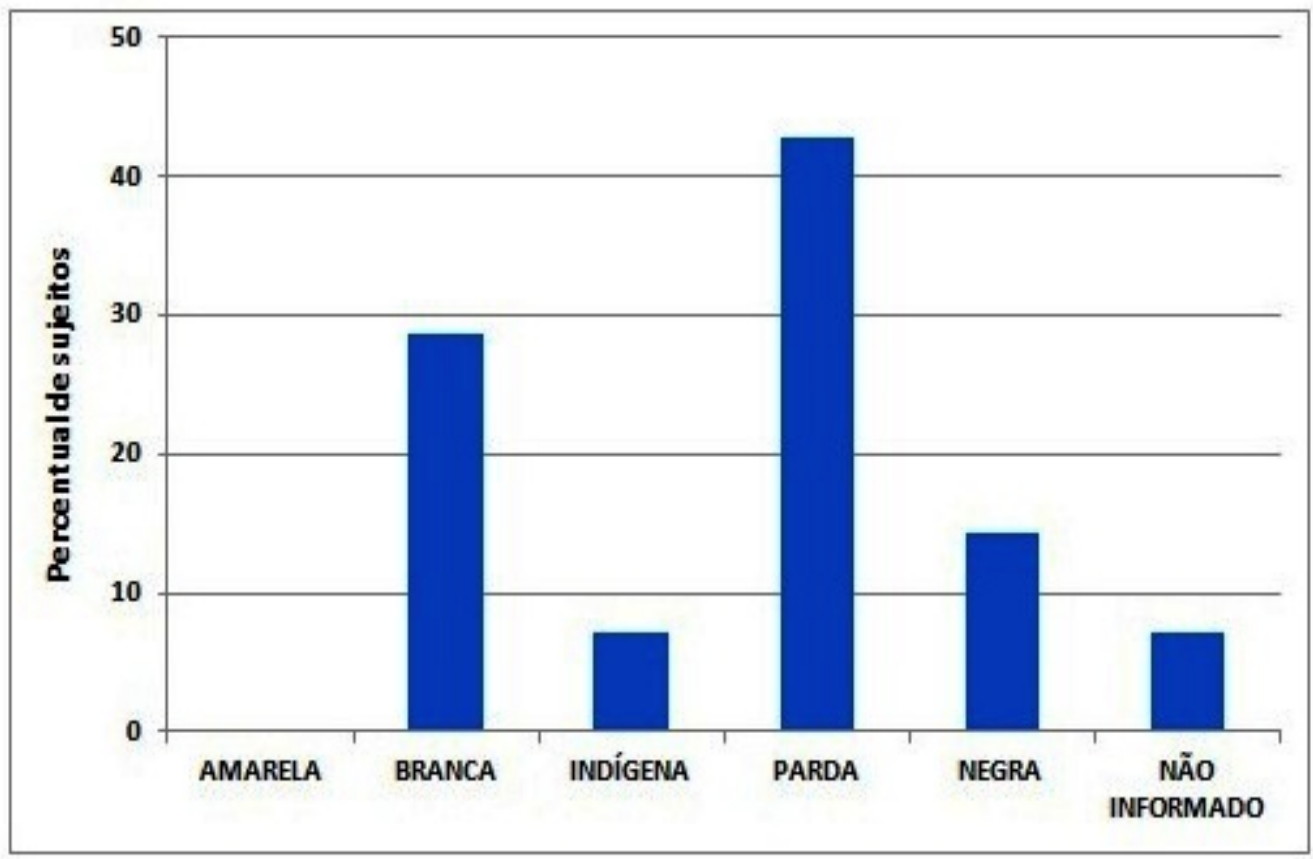

Fonte: Elaborado pelas autoras, a partir dos dados coletados.

Figura 10: Caracterização étnica dos sujeitos da Instituição 2

As três respostas mais frequentes entre os estudantes da Instituição 2, sobre a concepção de Ciência, mostram que esses indivíduos relacionam Ciência ao conhecimento ou descoberta, à 
maneira de entender o mundo e ao estudo aprofundado de algo, como apresentado pela Figura 11.

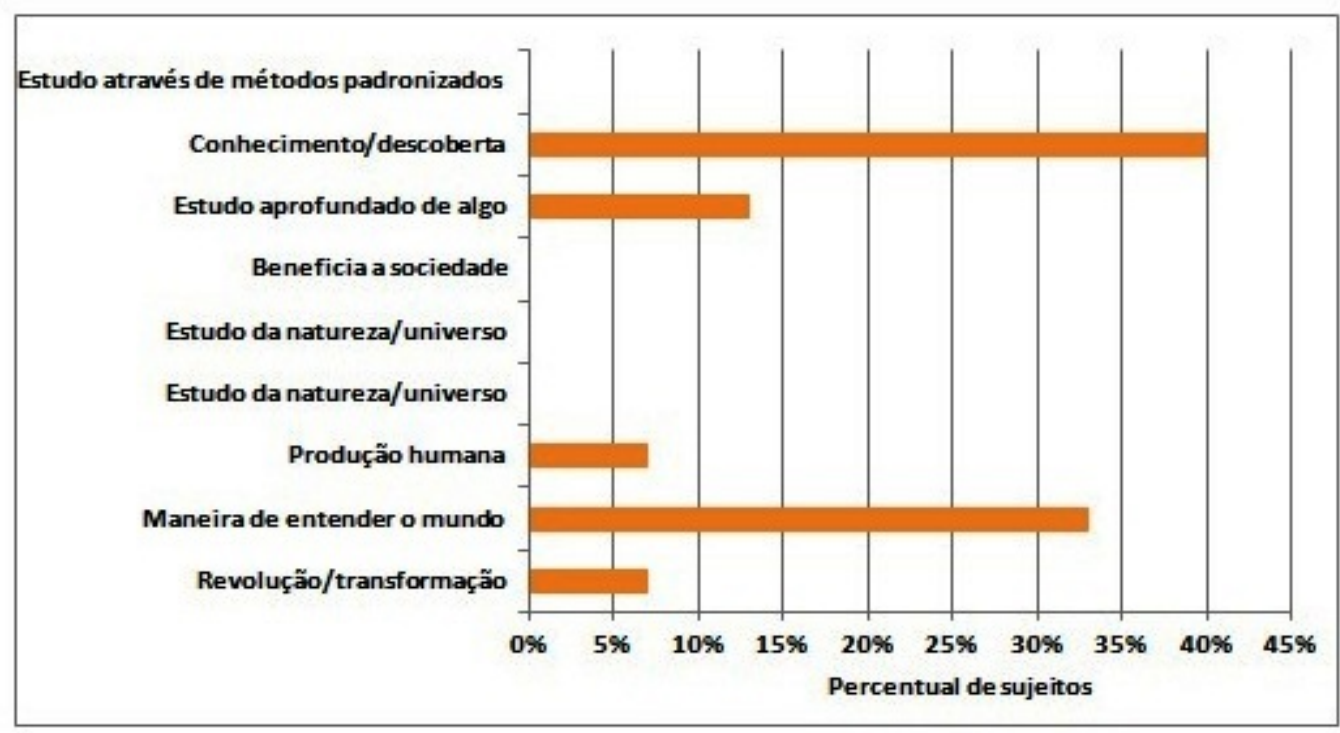

Fonte: Elaborado pelas autoras, a partir dos dados coletados.

Figura 11: Concepção de ciência dos sujeitos da Instituição 2

Para buscar informações sobre Ciência, cerca de 50\% dos estudantes da Instituição 2 recorrem a canais específicos do YouTube, enquanto aproximadamente 40 \% não acessam nenhum canal específico para se informar sobre o assunto, como pode ser observado na Figura 12. Interessante observar que, neste grupo, a escola não foi citada como fonte de informação, em nenhum momento. No entanto, para o grupo que mencionou a falta de interesse em procurar canais específicos para se informar sobre o assunto, provavelmente, a escola seja o único local onde esse tipo de informação seja obtida.

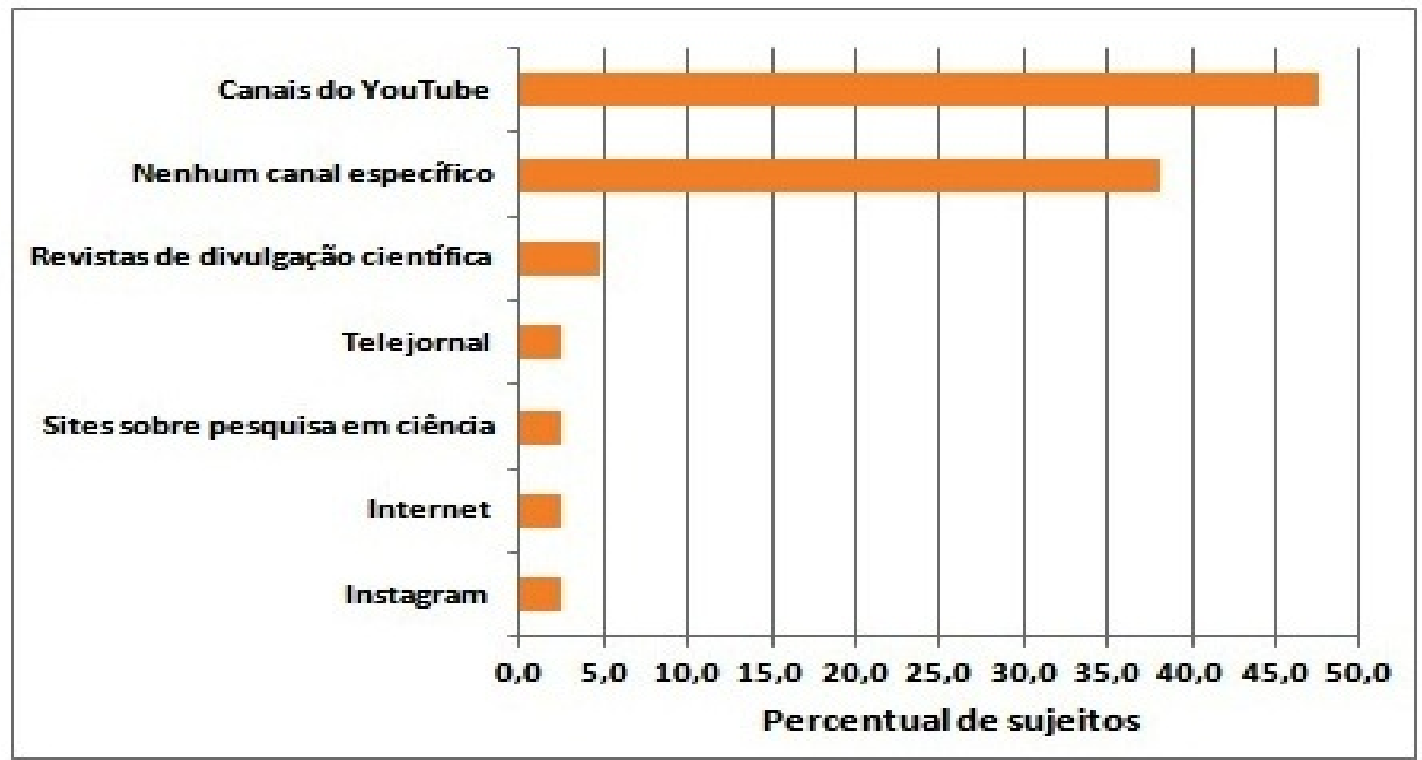

Fonte: Elaborado pelas autoras, a partir dos dados coletados.

Figura 12: Fontes de informação sobre ciência dos sujeitos da Instituição 2 
Há alguns anos, os canais de vídeo no YouTube, chamados de Vlogs, abordam assuntos ligados às Ciências e à tecnologia. Muitos ganharam notoriedade devido à divulgação científica realizada na internet. De acordo com o pesquisador do Laboratório de Estudos Avançados em Jornalismo da Universidade Estadual de Campinas (Labjor - UNICAMP), Rafael Evangelista, em entrevista à Revista FAPESP (PIERRO, 2016), os donos desses canais são geralmente pesquisadores ou estudantes de cursos de graduação e pós-graduação e estão conseguindo atingir a um público cada vez mais diversificado.

Em 2016, foi criada a comunidade de divulgação científica da internet ScienceVlogs Brasil (SVBR) que tinha como missão realizar a curadoria de canais com conteúdo científico e certificar o selo de qualidade e confiabilidade aos canais e, de acordo com o Instituto de Física da Universidade de São Paulo - USP, em 2019 a comunidade cresceu:

[...] canais-membros como Ponto em Comum e BláBláLogia, por exemplo, saltaram de poucas centenas ou nenhum inscrito para 150 mil e 170 mil seguidores, respectivamente. Outro campeão de audiência com o selo, o Ciência Todo Dia, saiu de 100 mil inscritos em 2016 para 730 mil em maio de 2019. A comunidade inclui ainda pesos-pesados já tradicionais da divulgação científica do YouTube no país, como o Canal do Pirula (quase 800 mil inscritos), Matemática Rio (1,5 milhão de assinantes) e Schwarza - Poligonautas (quase 900 mil seguidores) (LOPES, 2019).

Esses canais abrangem temas das áreas das Ciências naturais (astronomia, física, biologia) e, também, das áreas das Ciências Humanas (história, arqueologia, antropologia), além do interesse pela cultura POP. Há a presença de jovens cientistas, professores de ensino médio e jornalista da Ciência. A partir de abril de 2020, o isolamento social, imposto como medida sanitária imperativa para conter a disseminação do vírus SARS-CoV-2, levou as instituições de pesquisa e ensino a pensarem em estratégias pedagógicas que transcendessem seus espaços físicos. Assim, foram organizadas diversas lives, ${ }^{4}$ principalmente com o tema "Educação em saúde", para esclarecer a população sobre aspectos da pandemia de COVID-19 (NEVES et al, 2021)

O Ministério da Ciência, Tecnologia, Inovações e Comunicações (MCTIC) e o Centro de Gestão e Estudos Estratégicos (CGEE) realizaram, em 2019, a quinta edição da pesquisa acerca da percepção pública sobre a Ciência e a tecnologia (C\&T) no Brasil (as anteriores aconteceram nos anos de 1987; 2006; 2010 e 2015). De acordo com os resultados, a maioria dos brasileiros continua otimista em relação à $C \& T$, pois consideram que seus produtos causam mais benefícios do que malefícios à sociedade (CGEE, 2019). Na opinião de grande parte da população brasileira, os cientistas "são pessoas inteligentes, que fazem coisas úteis à humanidade". Reconhecem a necessidade de investimento em pesquisas científicas e as fontes de informação sobre Ciência que consideram mais confiáveis são os médicos, seguidos dos jornalistas e pesquisadores de universidades públicas (CGEE, 2019). Este dado foi encontrado também em parte dos sujeitos que participaram da pesquisa na Instituição 1 do presente trabalho.

Para Berger e Luckmann (1966, 2018), conhecimentos muito específicos tornam-se herméticos a estranhos. É o caso da medicina, na qual a própria vestimenta austera e a linguagem incompreensível dos médicos mantêm esses especialistas dentro de uma comunidade que detém o conhecimento que é capaz de afastar os leigos do horror causado pela doença e pela morte, o que, naturalmente, leva estes últimos a serem convencidos a confiar nas informações por eles fornecidas e obedecer às suas instruções. No nosso entender, esse aspecto, ressaltado por Berger

\footnotetext{
${ }^{4}$ Transmissões virtuais, ao vivo, de áudio e vídeo, geralmente realizadas em redes sociais.
} 
e Luckmann pode ajudar na interpretação de nossos dados de duas maneiras: primeiramente, seria uma forma de justificar a procura de informações em páginas específicas da web sobre pesquisas em Ciência, por aqueles sujeitos interessados no assunto, e, em segundo lugar, como justificativa para o distanciamento desse tipo de conhecimento por outros sujeitos que consideram uma área muito específica e de difícil compreensão.

No entanto, a maioria da população admite não ter o costume de procurar informações específicas sobre Ciência e, quando o fazem, utilizam principalmente os programas de TV, a internet e as redes sociais. Houve uma queda na participação da população em atividades de C\&T e em visitas a espaços de difusão científica, mostrando que, apesar de demonstrarem interesse pelo assunto, não consideram essas atividades prioritárias, além de estarem fora de seu alcance, por questões financeiras (CGEE, 2019). Esses dados coincidem com a falta de interesse de grande parte dos sujeitos da instituição 2 , que atende jovens socialmente vulneráveis. Vale ressaltar também a carência de centros de Ciências Humanas e Naturais em nosso país, o que, aliado a outras manifestações culturais regionais, como artes plásticas, dança, teatro e música, muito contribuiria para o desenvolvimento de uma cultura científica (CANDOTTI, 2002), principalmente naquelas localidades onde o acesso à internet é precário ou inexistente.

As fontes de acesso às informações científicas coincidem com aquelas preferidas pelos sujeitos pesquisados no presente trabalho nas duas Instituições educacionais. A Instituição 2 contou com uma amostra de estudantes oriundos de famílias com baixo poder aquisitivo e cerca de $40 \%$ desse público não costuma procurar informações específicas sobre Ciência, o que se alinha com os resultados obtidos no relatório do CGEE.

Empregando questionário elaborado pela Fundação Centro de Ciências e Educação Superior a Distância do Estado do Rio de Janeiro (Cecierj), Carvalho (2021) realizou um levantamento de concepções sobre Ciência e sua importância social, entre alunos do $3^{\stackrel{0}{-}}$ ano do ensino médio de um colégio estadual de Macaé. Conforme os resultados, apesar de os alunos terem mostrado conhecimentos de conceitos científicos e perceberem que a Ciência e a tecnologia têm impactos relevantes na sociedade, não se sentem seguros para aplicar esses conhecimentos em seu cotidiano e enfrentar situações que envolvam tomadas de decisões (CARVALHO, 2021). Da mesma forma, no presente trabalho, nenhum dos sujeitos, que aceitaram participar da pesquisa, fez qualquer comentário que relacionasse os conhecimentos científicos ao seu cotidiano.

No entanto, como ressaltam Castelfranchi et al (2013), é necessário realizar enquetes, entrevistas e grupos focais com públicos específicos, entre eles crianças, adolescentes e professores para diminuir o viés gerado pelas respostas fornecidas, que podem indicar que o respondente busca responder o que o pesquisador espera ouvir. Além disso, esses recursos metodológicos são fundamentais para que se conheça melhor o grupo com o qual se está trabalhando, e seja possível compreender, por meio da Teoria das Representações Sociais, os relacionamentos e as articulações estabelecidos entre o objeto de estudo (no caso, a percepção de Ciência) e outros objetos comuns no cotidiano desse grupo, bem como a maneira como os indivíduos reelaboram esses objetos, de acordo com o significado que apresentam para eles (MOSCOVICl, 1961, 2012).

\section{CONCLUSÃO}

O presente trabalho teve como objetivo realizar um estudo preliminar sobre as Representações sociais de Ciência elaboradas por jovens que estão cursando o Ensino Médio, bem 
como as principais fontes que eles utilizam para se informar sobre Ciência. Os resultados apontaram que a maior parte dos sujeitos da pesquisa associa a Ciência ao conhecimento ou a descoberta, considerando sua importância para a compreensão dos fenômenos do mundo que nos cerca. Os sujeitos relacionam, ainda, a Ciência com elementos da natureza e do universo e destacam a necessidade da utilização de métodos padronizados para o desenvolvimento de estudos nessa área de conhecimento. No entanto, apesar de terem mencionado os benefícios que a Ciência pode trazer à sociedade, não se observou relação entre Ciência e Tecnologia e nem foram considerados os impactos ambientais advindos do desenvolvimento tecnológico. Assim, a despeito de demonstrarem conhecimento básico e formularem ideias coerentes sobre o assunto, elaboram uma concepção de Ciência neutra, sem controvérsias e descontextualizada do cotidiano, assim como não são abordados os aspectos éticos dessa produção cultural humana.

Enquanto em uma das Instituições estudadas os sujeitos consideraram a escola como uma importante fonte de informação sobre Ciência, junto com os telejornais, na outra Instituição a escola nem foi mencionada, e, para esses sujeitos, os noticiários de TV tiveram pouca expressividade. Parece, no entanto, que entre os jovens, de um modo geral, as fontes tecnológicas de informação, principalmente as redes sociais, como Instagram e YouTube, exercem especial atração. Frente ao isolamento social que se estabeleceu, durante a pandemia de COVID-19, e às excessivas informações errôneas que passaram a circular pelas redes sociais, diversos professores e cientistas perceberam a necessidade de veicular conteúdos didáticos, principalmente relacionados à educação para a saúde, com o propósito de esclarecer a população sobre o assunto. Essa prática, aplicada a outros temas relacionados à Ciência, pode contribuir para o desenvolvimento de uma cultura científica em nossa sociedade, em todo caso que impacte o público jovem.

Considerando que as Representações Sociais se constroem e se mantêm por meio das informações que circulam nos meios de comunicação e das interações sociais cotidianas, o conhecimento das Representações Sociais sobre Ciência que os jovens elaboram, bem como das fontes de informação que eles consultam, pode auxiliar os professores na elaboração de estratégias didáticas que despertem para uma leitura crítica do que seja Ciência, das formas de construção do conhecimento científico, dos aspectos éticos do fazer científico e do impacto da ciência na sociedade e no meio ambiente, reconhecendo, assim, a aplicação do "duplo" escolar dos conhecimentos científicos no seu cotidiano.

\section{AGRADECIMENTOS}

As autoras agradecem o apoio da Universidade Estácio de Sá (UNESA) pela concessão da bolsa de estudos do Programa de Doutorado em Educação. Agradecimento ao Conselho Nacional de Desenvolvimento Científico e Tecnológico - CNPq pela bolsa de Produtividade em Pesquisa, processo 312360/2020-7.

\section{REFERÊNCIAS}

ALVES-MAZZOTTI, Alda Judith; CAMPOS, Pedro Humberto Faria. Cibercultura: uma nova "era das representações sociais"? In: ALMEIDA, Angela M.O.S.; TRINDADE, M.F. e ARAÚJO, Z. (eds.) Teoria das representações sociais - $\mathbf{5 0}$ anos. Rio de Janeiro: TechnoPolitik Editora, p. 159-176, 2014.

ANDRADE, Rodrigo de Oliveira Laços em recuperação: estudo registra altos índices de confiança da sociedade na Ciência em meio à pandemia. Revista Pesquisa FAPESP, São Paulo, edição 292, junho 
2020. Disponível em: https://revistapesquisa.fapesp.br/lacos-em-recuperacao/, Acesso em: 20 set 2021.

ARANTES, Shirley de Lima Ferreira; PERES, Simone Ouvinha. Metodologias ativas em programas e projetos de Iniciação Científica, Educação Científica e Divulgação Científica. Brazilian Journal of Development, Curitiba, v. 7, n. 2, p. 13496-13515, 2021.

BARDIN, Laurence. Análise de conteúdo. Tradução de Luís Antero Reto, Augusto Pinheiro. 3a impressão da 1a edição. São Paulo: Edições 70, 2016.

BERGER, Peter L.; LUCKMANN, Thomas. A construção social da realidade: tratado de sociologia do conhecimento. 36 ed.; tradução de Floriano de Souza Fernandes. Petrópolis: Vozes, 2014; 4a reimpressão, 2018.

CALDAS, Graça. Mídia e políticas públicas para a comunicação da Ciência. In PORTO, CM., BROTAS, AMP., and BORTOLIERO, ST., orgs. Diálogos entre Ciência e divulgação científica: leituras contemporâneas [online]. Salvador: EDUFBA, pp. 19-36, 2011. Disponível em https://static.scielo.org/scielobooks/y7fvr/pdf/porto-9788523211813.pdf, acesso em 26 de maio de 2021.

CANDOTTI, Ennio. Ciência na educação popular. In MASSARANI, Luísa; MOREIRA, Ildeu de Castro; BRITO, Fátima (orgs.). Ciência e público: caminhos da divulgação científica no Brasil. Rio de Janeiro. Fórum de Ciência e Cultura, 2002.

CARVALHO, Jaciara de Sá. Redes e comunidades: ensino-aprendizagem pela Internet. São Paulo: Editora e Livraria Instituto Paulo Freire, 2011.

CARVALHO, Stella Marys Meneses. Levantamento de concepções sobre Ciência e sua importância social entre alunos do $3^{\circ}$ ano do ensino médio do Colégio Estadual Matias Neto. Monografia para obtenção do título de Licenciado em Biologia, na Universidade do Norte Estadual Darcy Ribeiro, Macaé, RJ. 19pp. Publicado em fevereiro de 2021. Disponível em https://monografias.brasilescola.uol.com.br/educacao/levantamento-de-concepcoes-sobreciencia-e-sua-importancia-social-entre-alunos-de-3-ano-do-ensino-medio-do-colegio-estadualmatias-neto-macae-ri.htm Acesso em: 29 maio 2021.

CAVALHEIRO, Glauco; BRANDÃO, Carolina Gandon. Comunicação e Retórica: um contexto para pensar a pós-verdade. In GUARESCHI, Pedrinho Arcides; AMON, Denise; GUERRA, (orgs.).

Psicologia, comunicação e pós-verdade. Florianópolis: ABRAPSO, p. 89-106, 2019.

CASTELFRANCHI, Yurij et al. As opiniões dos brasileiros sobre Ciência e tecnologia: o 'paradoxo' da relação entre informação e atitudes. História, Ciências, Saúde - Manguinhos, 20, 1163-1183, 2013.

CGEE. Centro de Gestão de Estudos Estratégicos. Percepção pública da C\&T no Brasil - 2019. Resumo executivo. Brasília, DF: 24p, 2019. 
CHAMON, Edna Maria Q. O.; SANTANA, Leonor M. Representação social, ciência e educação no século XXI - para onde vamos? In: ROSO, Adriane et al. (org.). Mundos sem fronteiras.

Representações sociais e práticas psicossociais. Porto Alegre: ABRAPSO, 2021

COSTA, Otávio Barduzzi Rodrigues. Onde estamos? Considerações sobre a modernidade, negacionismo, Ciência e a Covid-19. Boletim de Conjuntura, Boa Vista, ano II, vol. 3, n. 8, p. 22-35, 2020.

ELIAN, Samir. A importância e os desafios de se comunicar Ciência no Brasil em tempos de Covid19. Blogs de Ciência da Universidade Estadual de Campinas, Campinas, 06 abril 2021. Disponível em https://www.blogs.unicamp.br/covid-19/a-importancia-e-os-desafios-de-se-comunicarciencia-no-brasil-em-tempos-de-covid-19/, abril de 2021, acesso em 30 de maio de 2021.

EQUIPE DE JORNALISMO VISUAL DA BBC NEWS BRASIL. Os 6 tipos de mensagens enganosas mais comuns contra as vacinas de COVID-19 nas redes sociais e o que diz a Ciência sobre elas, BBC NEWS BRASIL, Brasil, 17 de maio de 2021. Disponível em:

https://www.bbc.com/portuguese/resources/idt-c47d82b0-2ff7-4795-95f4-f84de9ae7581_acesso em: 29 maio 2021.

GUARESCHI, Pedrinho Arcides; AMON, Denise; GUERRA, (orgs.). Psicologia, comunicação e pósverdade. Florianópolis: ABRAPSO, p. 89-106, 2019.

HARARI, Yuval Noah. Maior perigo não é o vírus, mas ódio, ganância e ignorância. Deutsche Welle, Alemanha. Entrevistadora Anna Carthaus, em 26 abril 2020. Disponível em https://p.dw.com/p/3bMlu

LENT, Roberto. A Ciência por dentro. Blog do Jornal O Globo, 11 junho 2020. Disponível em https://blogs.oglobo.globo.com/a-hora-da-ciencia/post/ciencia-por-dentro.html. Acesso em 29 de maio de 2021.

LOPES, Reinaldo José. SVBR (Science Vlogs Brasil) entra em nova fase para ampliar alcance da Ciência no YouTube. Instituto de Física da Universidade de São Paulo, 31 maio 2019. Disponível em: https://portal.if.usp.br/ifusp/pt-br/not\%C3\%ADcia/svbr-science-vlogs-brasil-entra-em-novafase. Acesso em: 21/06/2021

MAZZOTTI, Tarso B. Ensino de conceitos científicos ou de suas representações sociais. In: CHAMON, E. M. Q. O.; GUARESCHI, P. A.; CAMPOS, P. H. F. Textos e debates em representações sociais. Porto Alegre, ABRAPSO, 2014.

MOREIRA, Ildeu de Castro; MASSARANI, Luísa. Aspectos históricos da divulgação científica no Brasil. In MASSARANI, Luísa; MOREIRA, Ildeu de Castro; BRITO, Fátima (orgs.). Ciência e público: caminhos da divulgação científica no Brasil. Rio de Janeiro. Fórum de Ciência e Cultura, 2002.

MOSCOVICl, Serge. A psicanálise: sua imagem e seu público. Tradução de Sônia Fuhrmann. Petrópolis: Vozes, 2012. 
MOSCOVICI, Serge. Representações Sociais: investigações em Psicologia Social. Tradução de Pedrinho A. Guareschi. Petrópolis: Vozes, 11a edição, 2015; 4aㅡ reimpressão, 2019.

MOVIMENTO antivacina usa pandemia do coronavírus como megafone. Agence France Presse. Revista Isto é, 24 abril 2021. Disponível em https://istoe.com.br/movimento-antivacina-usapandemia-do-coronavirus-como-megafone/, acesso em 30 de maio de 2021.

NEVES, Vanusa Nascimento Sabino et al. Utilização de lives como ferramenta de educação em saúde durante a pandemia pela COVID-19. Educ.Soc., Campinas, v. 42, p. 1-17, 2021.

PALMONARI, Augusto; CERRATO, Javier. Representações Sociais e Psicologia Social. In: ALMEIDA, Angela Maria de Oliveira; SANTOS, Maria de Fática de Souza; TRINDADE, Zeidi Araúdo (orgs.). Teoria das Representações Sociais: 50 anos. 898p. Brasília: Technopolitik, 2014.

PEDROSO, Polyana Raquel; GISI, Maria Lourdes. A pandemia - Covid 19 e os impactos na juventude: educação e trabalho. Revista Praxis, Volta Redonda-RJ, v. 12, n. 1, p. 185-194, 2020.

PIERRO, Bruno de. Youtubers na Ciência Canais de vídeo ganham destaque na divulgação de pesquisas feita na internet. Revista Pesquisa FAPESP, São Paulo, edição 243, de maio 2016. Disponível em: https://revistapesquisa.fapesp.br/youtubers-na-ciencia/. Acesso em: 21/06/2021.

REIS, José. Ponto de vista: José Reis. In MASSARANI, Luísa; MOREIRA, Ildeu de Castro; BRITO, Fátima (orgs.). Ciência e público: caminhos da divulgação científica no Brasil. Rio de Janeiro. Fórum de Ciência e Cultura, 2002.

REIS, Pedro; RODRIGUES, Sara; SANTOS, Filipa. Concepções sobre os cientistas em alunos do 1은 ciclo do Ensino Básico: "Poções, máquinas, monstros, invenções e outras coisas malucas". Revista Electrónica de Enseñanza de las Ciencias, Vol. 5 № 1, p. 51-74, 2006.

RODRIGUES, Alvori et al. Concepções sobre ciência e fazer científico de estudantes de um curso normal e possíveis implicações nas atitudes futuras desses professores. Alexandria: Revista de Educação em Ciência e Tecnologia, v. 12, n. 2, p. 65-92, 2019.

SANTOS, Absalon A. et al. A representação social da biologia entre alunos do ensino médio: implicações educativas e profissionais a partir das redes semânticas. Acta Scientiae Biological Research, [S. I.], v. 2, n. 1, p. 73-95, 2017.

SERRÃO, Luís Felipe Soares et al. A experiência de um indicador de letramento científico. Cadernos de Pesquisa, v. 48, n. 160, p. 334-361, 2016. 